\title{
Acute volume reduction with aortic valve replacement immediately improves ventricular mechanics in patients with aortic regurgitation
}

\author{
Shigeki Morita, MD \\ Yoshie Ochiai, MD \\ Yoshihisa Tanoue, MD \\ Manabu Hisahara, MD \\ Munetaka Masuda, MD \\ Hisataka Yasui, MD
}

\footnotetext{
From the Department of Cardiovascular Surgery, Faculty of Medicine, Kyushu University, Fukuoka, Japan.

Received for publication June 27, 2002; revisions requested July 26,2002 ; revisions received Sept 9, 2002; accepted for publication Sept 13, 2002.

Address for reprints: Shigeki Morita, MD, Department of Cardiovascular Surgery, Faculty of Medicine, Kyushu University, 3-1-1 Maidashi, Higashi-ku, Fukuoka 8128582, Japan (E-mail: morita@ heart.med. kyushu-u.ac.jp).

J Thorac Cardiovasc Surg 2003;125:283-9

Copyright $\odot 2003$ by The American Association for Thoracic Surgery

$0022-5223 / 2003 \$ 30.00+0$

doi: $10.1067 / \mathrm{mtc} .2003 .20$
}

Objectives: Few data have been available regarding the immediate response in ventricular mechanics to acute volume reduction caused by aortic valve replacement for aortic regurgitation.

Methods: We studied 9 patients in the operating room immediately before and after the institution of cardiopulmonary bypass. Left ventricular pressure and crosssectional area (a surrogate of left ventricular volume) were measured with a catheter-tip manometer and a transesophageal echocardiographic system equipped with automated border-detection technology. Left ventricular pressure-area loops were constructed, and the caval occlusion method was used to obtain the slope of the end-systolic pressure-area relationship and the end-systolic area associated with 100 $\mathrm{mm} \mathrm{Hg}$. From the steady-state beats, stroke area was obtained by subtracting the minimum area from the maximum area. Effective arterial elastance, a measure of ventricular afterload, was calculated from end-systolic pressure, and stroke area as follows: effective arterial elastance equals end-systolic pressure divided by stroke area.

Results: Reductions in maximum area $\left(21.0 \pm 8.5\right.$ to $16.0 \pm 6.8 \mathrm{~cm}^{2}$ [SD] $)$ and minimum area $\left(15.3 \pm 8.4\right.$ to $\left.12.0 \pm 6.1 \mathrm{~m}^{2}\right)$ shifted the baseline pressure-area loops to the left. The slope of the end-systolic pressure-area relationship (11.6 \pm 4.8 to $16.0 \pm 7.5 \mathrm{~mm} \mathrm{Hg} / \mathrm{cm}^{2}$ ) and afterload (effective arterial elastance, $17.9 \pm 11.6$ to $26.3 \pm 16.4 \mathrm{~mm} \mathrm{Hg} / \mathrm{cm}^{2}$ ) were increased, and the end-systolic area associated with $100 \mathrm{~mm} \mathrm{Hg}$ was reduced $\left(18.3 \pm 10.0\right.$ to $\left.13.7 \pm 5.8 \mathrm{~cm}^{2}\right)$.

Conclusion: Correction of volume overload reduced preload (minimum area), shifted the end-systolic pressure-area relationship to the left (decreased end-systolic area), and improved ventricular contractility (increased slope of the end-systolic pressure-area relationship). The result indicated that acute volume reduction favorably influenced ventricular mechanical parameters immediately after the operation.

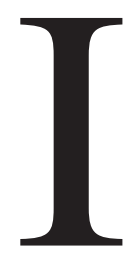

mprovement in ventricular function caused by load-reduction therapy is a well-established concept in the treatment of congestive heart failure. The immediate effect of acute load alteration on ventricular function is not clearly understood, however. In patients with aortic regurgitation (AR), the elimination of regurgitant volume by means of aortic valve replacement (AVR) causes significant reduction in left ventricular (LV) end-diastolic volume or preload. ${ }^{1}$ In general, reduction in preload results in a decrease in blood pressure. Thus when preload is reduced, an improvement in contractility, an increase in afterload, or both should accompany the maintenance of adequate blood pressure. 
There have been few data available, however, to show the restoration of LV contractility immediately after AVR in the operating room.

Accordingly, the current study was designed to elucidate the interrelationship among preload, afterload, and contractility immediately before and after AVR in patients with AR. For this purpose, we applied the framework of the LV pressure-volume relationship ${ }^{2}$ and the concept of ventricleafterload coupling. ${ }^{3}$ We used transesophageal echocardiography (TEE) with the capability of automated border detection (ABD), which provided online output of the ventricular cavity area measurement. Because there is a close relationship between LV volume and short-axis cross-sectional area (CSA), ${ }^{4,5}$ CSA has been used as a surrogate of LV volume. Combining LV pressure and CSA yields LV pressure-area loops, which could be used to apply the framework of LV pressure-volume relationship. With this approach, we measured end-systolic elastance (Ees; contractility) and effective arterial elastance (Ea; afterload) to elucidate the mechanism of the response of LV performance after AVR.

\section{Patients and Methods}

Nine male patients (age range, 38-74 years; median, 66 years) who underwent elective AVR for the correction of pure AR were studied in the operating room. LV ejection fraction (EF) measured by means of a preoperative catheterization study was normal (mean, $57 \% \pm 10 \%[\mathrm{SD}]$ ), with increased end-diastolic volume index $\left(236 \pm 64 \mathrm{~mL} / \mathrm{m}^{2}\right)$ and end-systolic volume index $(114 \pm 50$ $\left.\mathrm{mL} / \mathrm{m}^{2}\right)$. LV end-diastolic pressure was moderately increased $(17.5 \pm 6.6 \mathrm{~mm} \mathrm{Hg})$, with a normal cardiac index $(3.1 \pm 0.9 \mathrm{~L}$. $\min ^{-1} \cdot \mathrm{m}^{-2}$ ). All patients had grade $4 / 4 \mathrm{AR}$, except for 2 patients who had grade 3/4 AR. The study was approved by the institutional review board of the Faulty of Medicine, Kyushu University. Informed written consent was obtained from all patients. In the operating room a radial artery line was inserted after achievement of local anesthesia. After the induction of general anesthesia, a 7.5F thermodilution pulmonary artery catheter (model $93-\mathrm{A} 431 \mathrm{H}$; Baxter Healthcare Corp, Irvine, Calif) was positioned through the right internal jugular vein. The heart was exposed through a median sternotomy and a longitudinal incision of the pericardium. Heparin was given, and arterial and venous cannulas were inserted and connected to a heart-lung machine. Tapes were passed around the superior and inferior venae cavae. A catheter-tipped manometer (MPC 350; Millar Instruments, Inc, Houston, Tex) or a fiberoptic catheter (Sentron, AC Roden, The Netherlands) was inserted through the stab wound of the left ventricle or through the right upper pulmonary vein through the mitral valve. A $5-\mathrm{MHz}$ omniplane TEE probe (model HP 21362C; Hewlett-Packard, Andover, Mass) that had been inserted after the induction of anesthesia was positioned to obtain a cross-sectional view of the left ventricle at the level of the midpapillary muscle. Echocardiographic images were acquired by using a Hewlett-Packard Sonos 2500 echocardiographic system (model M2406A, Hewlett-Packard) with an $\mathrm{ABD}$ capability. A region of interest was drawn manually immediately beyond the LV endocardial border to exclude low-density ultrasound signals that might appear within the lateral myocardium. Once the image had been established, the same region of interest and the gain setting were maintained throughout the protocol for each patient.

\section{Protocol}

After the adequate placement of the TEE probe, thermodilution cardiac output was measured, and LV pressure and CSA were recorded simultaneously to obtain steady-state baseline data. Using the tape passed around the inferior vena cava, we occluded the cava to obtain multiple beats with different preload. The quality of the recorded data was checked immediately. When satisfactory recordings were obtained, cardiopulmonary bypass was instituted, and a routine AVR was performed. The same measurement was performed within 5 minutes after the discontinuation of cardiopulmonary bypass before removing the cannulas and neutralizing heparin. The postcardiopulmonary bypass measurement took no more than 10 minutes.

\section{Data Acquisition and Analysis}

Pressures of the left ventricle, the radial artery, the pulmonary artery, and the right atrium along with lead II echocardiographic signals and LV area signals from the echocardiography machine were digitized online at $200 \mathrm{~Hz}$ with an analog-to-digital converter (Mac Lab System; AD Instruments, Ltd, Dunedin North, New Zealand). These signals were recorded on a hard disk of a laptop computer (Macintosh Power Book 550C; Apple Computer, Inc, Cupertino, Calif), and LV pressure and area signals were plotted to display pressure-area loops. There is a delay in LV area signal because of the signal processing. Our preliminary study directly comparing ventricular volume obtained from a conductance catheter and area signal from ABD showed that the delay was $40 \mathrm{~ms}$. Accordingly, we advanced the LV area signal by $40 \mathrm{~ms}$ in all patients.

From the steady-state beats, maximal CSA (Amax) and minimal CSA (Amin) were obtained. Stroke area (SA; SA = Amax Amin) and fractional area change (FAC; FAC $=$ SA/Amax) were calculated. SA and FAC were used as the echocardiographic equivalents of stroke volume and $\mathrm{EF}$, respectively.

Contractility was assessed by using 3 indices: (1) Ees, ${ }^{2,6}$ which is the slope of the end-systolic pressure-area relationship (ESPAR); (2) the slope of the stroke work (SW) end-diastolic area (Aed) relationship $(\mathrm{Msw})^{7}$; and (3) the ratio of maximal dp/dt to Aed (dp/dt $\max _{\max }$ to Aed ratio). ${ }^{8}$ For ESPAR and SW-Amax relationships, area axis intercepts were measured as well (Ao,es and Ao,sw, respectively). The area associated with the LV end-systolic pressure (Pes) of $100 \mathrm{~mm} \mathrm{Hg}$ was calculated to determine the position of the ESPAR in the operating range as follows:

$$
A_{100}, e s=A o+100 / \text { Ees }
$$

Similarly, the position of the SW-Aed in the operating range was determined by calculating $\mathrm{A}_{500}$, sw. Diastolic function was assessed by fitting the end-diastolic pressure-area relationship to exponential function, and the stiffness constant $(\beta)$ was calculated as previously reported. ${ }^{9}$ By using the above obtained exponential function, the area that provides the end-diastolic pressure of $8 \mathrm{~mm}$ $\mathrm{Hg}$ was calculated $\left(\mathrm{A}_{8}\right.$,ed).

The effective arterial elastance, Ea, a measure of LV afterload, was calculated as Pes/SA, ${ }^{3}$ and the ventricle-afterload coupling 
TABLE 1. Conventional hemodynamic data

\begin{tabular}{lcccccccc}
\hline & $\begin{array}{c}\text { HR } \\
\left(\mathbf{m i n}^{-1}\right)\end{array}$ & $\begin{array}{c}\text { Prad,s } \\
(\mathbf{m m ~ H g})\end{array}$ & $\begin{array}{c}\text { Prad,d } \\
(\mathbf{m m ~ H g})\end{array}$ & $\begin{array}{c}\text { Prad,m } \\
(\mathbf{m m ~ H g})\end{array}$ & $\begin{array}{c}\text { Cl } \\
\left(\mathbf{L} \cdot \mathbf{m i n}^{-\mathbf{1}} \cdot \mathbf{m}^{-\mathbf{2}}\right)\end{array}$ & $\begin{array}{c}\text { LAP } \\
(\mathbf{m m ~} \mathbf{H g})\end{array}$ & $\begin{array}{c}\text { RAP } \\
(\mathbf{m m} \mathbf{H g})\end{array}$ & $\begin{array}{c}\text { SVRI } \\
\left(\mathbf{d y n e s} \cdot \mathbf{s}^{-\mathbf{1}} \cdot \mathbf{c m}^{-\mathbf{5}} \cdot \mathbf{m}^{-\mathbf{2}}\right)\end{array}$ \\
\hline Before & $73 \pm 14$ & $105 \pm 10$ & $38 \pm 9$ & $61 \pm 9$ & $2.7 \pm 0.8$ & $8.2 \pm 2.0$ & $4.4 \pm 0.8$ & $1913 \pm 950$ \\
After & $90 \pm 19$ & $93 \pm 15$ & $55 \pm 13$ & $68 \pm 15$ & $2.8 \pm 0.8$ & $7.0 \pm 2.1$ & $4.5 \pm 1.2$ & $1922 \pm 693$ \\
$P$ value & .011 & .169 & .027 & .316 & .781 & .243 & .851 & .987 \\
\hline
\end{tabular}

All values are expressed as means \pm SD. $H R$, Heart rate; Prad, $s$, systolic radial artery pressure; Prad, $d$, diastolic radial artery pressure; Prad, $m$, mean radial artery pressure; $C l$, cardiac index; $L A P$, left atrial pressure; $R A P$, right atrial pressure; $S V R I$, systemic vascular resistance index.

ratio was obtained (Ea/Ees). In addition, the systemic vascular resistance index, a standard parameter of afterload, was calculated as follows:

\section{([Mean arterial pressure}

$$
\text { - Right atrial pressure]/Cardiac index) } \times 80
$$

The total mechanical energy generated by means of ventricular contraction defined by pressure-volume area (PVA) ${ }^{10}$ was obtained as the area circumscribed by the end-systolic trajectory of the pressure-area loop, the end-systolic pressure-area line, and the end-diastolic pressure-area relationship. SW was calculated as the area inside the pressure-area loop. The efficiency of energy transfer from PVA to SW was evaluated as SW/PVA.

\section{Statistics}

Results are presented as means $\pm \mathrm{SD}$. A paired $t$ test was performed to compare the variables before and after AVR.

\section{Results}

All 9 patients underwent AVR with mechanical prostheses (Carbomedics, Austin, Tex). The ischemic time ranged from 31 to 124 minutes, with a median value of 61 minutes. No patients received inotropic or vasodilating agents. There were no study-related complications, and all patients were discharged with an uneventful postoperative course.

There was no change in conventional hemodynamic variables after AVR, except for increased heart rate and higher diastolic radial artery pressure (Table 1). During the vena caval occlusion, there was no significant increase in heart rate, but heart rate tended to increase after the release of occlusion. This phenomenon indicated that caval occlusion did cause a baroreflex response, but the reflex was not prompt enough to influence the data during vena caval occlusion. Representative LV pressure-area loops before and after AVR are shown in Figure 1. Because of the reduction in Amax and Amin, baseline loops were shifted to the left. The ESPAR also shifted to the left with an increase in the slope (Ees). It can be appreciated that there was no isovolumic relaxation phase caused by AR. The pressure at the start of ejection (the right shoulder of the loop) was lower before AVR, probably because of low diastolic arterial pressure. Ea, a parameter of afterload, was increased after AVR. Variables obtained from the baseline loops in all patients are summarized in Table 2. There was a $24 \%$ reduction in Amax and a $22 \%$ decrease in Amin. SA was reduced by $31 \%$. There was no change in FAC. The parameters of contractility are shown in Table 3 . There was an increase in Ees by $38 \%$, with no difference in the area axis intercept (Ao,es). A decrease in $\mathrm{A}_{100}$, es indicated that the operating points of the ESPAR were shifted to the left after AVR. The slope of the SW-Aed relationship was reduced by $31 \%$ (marginally significant, $P=.136$ ), which usually indicated reduced contractility. The reason for the decrease in Msw will be given in the "Discussion" section. A parameter fairly independent of preload ( $\mathrm{dp} / \mathrm{dt}_{\max }$ to Aed ratio $)^{8}$ was increased by $59 \%$. As shown in Table 4, Ea was increased by $46 \%$. Because there were similar increases in Ea and Ees, there was no significant change in the coupling ratio $\mathrm{Ea} / \mathrm{Ees}$. Because of the reduction in LV volume, PVA was reduced by $24 \%$, although the difference was marginal $(P=.128)$. The reduction in SW was $42 \%$. There was no change in SW/PVA. No difference was found in the parameters of diastolic function $\left(\beta\right.$ and $A_{8}$, ed).

\section{Discussion}

We found that in patients with pure AR, there was an improvement in contractile function, reduction in both preload and mechanical LV work, and increase in ventricular afterload immediately after AVR. We used a previously validated method ${ }^{4,5,11}$ of using the cross-sectional cavity area, obtained by means of echocardiography, as a surrogate for volume, which allowed us to apply the framework of LV pressure-volume relationship in the operating room. To the best of our knowledge, this is the first study to demonstrate improvement in contractile function immediately after AVR by using the framework of the pressure-volume relationship in patients with AR.

There was a significant improvement in ventricular contractility evidenced by the increase in the slope (Ees) and the leftward shift (decrease in $\mathrm{A}_{100}$, es) of the ESPAR. One might argue that in the presence of reduced LV volume after AVR, Ees was falsely high because there is an inverse relationship between Ees and the size of the ventricle. However, this might not be the case. First, this is because the observation was limited to the same subject (same heart) and we were not comparing Ees among the subjects with 

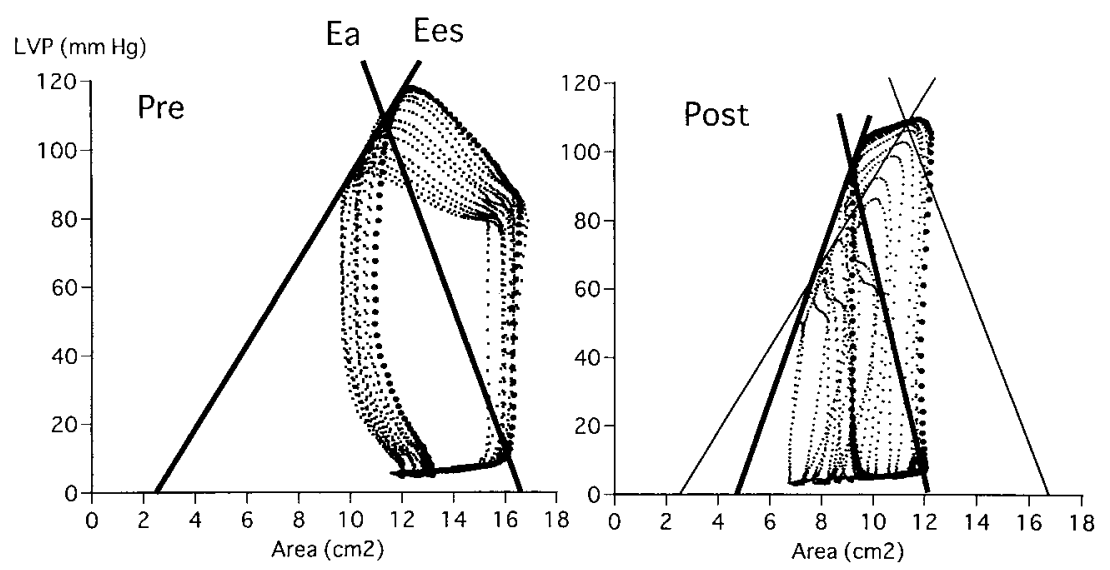

Figure 1. Representative pressure-area loops before (left panel) and after (right panel) AVR. Baseline loops are shown by large dots, and loops during caval occlusion are shown by small dots. Solid lines are the lines of Ees and Ea. In the right panel thin lines are the lines of Ees and Ea before AVR. LVP, LV pressure.

TABLE 2. Variables obtained from baseline loops

\begin{tabular}{lccccccc}
\hline & $\begin{array}{c}\text { Ped } \\
(\mathbf{m m ~ H g})\end{array}$ & $\begin{array}{c}\text { Pes } \\
(\mathbf{m m ~ H g})\end{array}$ & $\begin{array}{c}\text { Amax } \\
\left(\mathbf{c m}^{2}\right)\end{array}$ & $\begin{array}{c}\text { Amin } \\
\left(\mathbf{c m}^{2}\right)\end{array}$ & $\begin{array}{c}\text { SA } \\
\left(\mathbf{c m}^{2}\right)\end{array}$ & $\begin{array}{c}\text { FAC } \\
(\%)\end{array}$ & $\begin{array}{c}\text { dp/dt } \\
(\mathbf{m a x}\end{array}$ \\
\hline Before & $7.6 \pm 1.6$ & $88.7 \pm 17.0$ & $21.0 \pm 8.5$ & $15.3 \pm 8.4$ & $5.8 \pm 2.0$ & $30.4 \pm 14.0$ \\
After & $7.3 \pm 1.4$ & $89.8 \pm 22.5$ & $16.0 \pm 6.8$ & $12.0 \pm 6.1$ & $4.0 \pm 1.4$ & $26.8 \pm 9.1$ \\
$P$ value & .829 & .899 & .013 & .046 & .022 & $823 \pm 228$ \\
\hline
\end{tabular}

Ped, LV end-diastolic pressure; $d p / d t_{\text {max }}$ maximum value of the first derivative of LV pressure.

TABLE 3. Parameters of contractility

\begin{tabular}{|c|c|c|c|c|c|c|c|}
\hline & $\begin{array}{c}\text { Ees } \\
\left(\mathrm{mm} \mathrm{Hg} / \mathrm{cm}^{2}\right)\end{array}$ & $\begin{array}{l}\text { Ao,es } \\
\left(\mathrm{cm}^{2}\right)\end{array}$ & $\begin{array}{l}A_{100}, \text { es } \\
\left(\mathrm{cm}^{2}\right)\end{array}$ & $\begin{array}{c}\text { Msw } \\
(\mathrm{mm} \mathrm{Hg})\end{array}$ & $\begin{array}{l}\text { Ao,sw } \\
\left(\mathrm{cm}^{2}\right)\end{array}$ & $\begin{array}{c}A_{500}, s w \\
\left(\mathrm{~cm}^{2}\right)\end{array}$ & $\begin{array}{c}\mathrm{dp} / \mathrm{dt}_{\max } / \text { Aed } \\
\left(\mathrm{mm} \mathrm{Hg} \cdot \mathrm{s}^{-1} \cdot \mathrm{cm}^{-2}\right)\end{array}$ \\
\hline Before & $11.6 \pm 4.8$ & $6.6 \pm 5.7$ & $18.3 \pm 10.0$ & $68.9 \pm 14.1$ & $13.5 \pm 8.0$ & $21.0 \pm 8.0$ & $41.3 \pm 19.2$ \\
\hline After & $16.0 \pm 7.5$ & $5.7 \pm 3.9$ & $13.7 \pm 5.8$ & $49.8 \pm 30.9$ & $9.8 \pm 4.5$ & $22.2 \pm 6.7$ & $65.5 \pm 44.5$ \\
\hline$P$ value & .035 & .561 & .037 & .139 & .035 & .431 & .040 \\
\hline
\end{tabular}

Ao,es, Area-axis intercept of the end systolic pressure area relationships; $A_{100}$ es, end-systolic area that gives the Pes of $100 \mathrm{~mm} \mathrm{Hg} ; A 0, s w$, area-axis

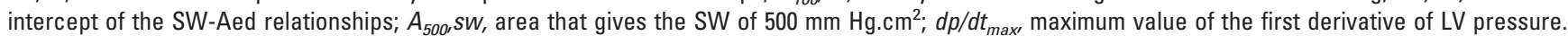

TABLE 4. Parameters and variables of afterload, energetics, and diastolic function

\begin{tabular}{|c|c|c|c|c|c|c|c|}
\hline & $\begin{array}{c}\text { Ea } \\
\left(\mathrm{mm} \mathrm{Hg} / \mathrm{cm}^{2}\right)\end{array}$ & $\mathrm{Ea} / \mathrm{Ees}$ & 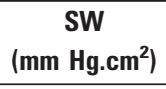 & $\begin{array}{c}\text { PVA } \\
\left(\mathrm{mm} \mathrm{Hg.cm}{ }^{2}\right)\end{array}$ & SW/PVA & $\boldsymbol{\beta}$ & $A_{8}, \mathrm{ed}\left(\mathrm{cm}^{2}\right)$ \\
\hline Before & $17.9 \pm 11.6$ & $1.98 \pm 1.72$ & $447 \pm 135$ & $1082 \pm 430$ & $0.45 \pm 0.16$ & $0.14 \pm 0.07$ & $19.9 \pm 10.1$ \\
\hline After & $26.3 \pm 16.4$ & $1.89 \pm 1.38$ & $258 \pm 103$ & $820 \pm 458$ & $0.34 \pm 0.12$ & $0.15 \pm 0.11$ & $16.7 \pm 6.9$ \\
\hline$P$ value & .010 & .720 & .003 & .128 & .030 & .704 & .271 \\
\hline
\end{tabular}

$\beta$, Stiffness constant of the end-diastolic pressure-area relationship; $A_{8^{\prime}}$ ed, area associated with an end-diastolic pressure of $8 \mathrm{~mm} \mathrm{Hg}$.

different ventricular sizes. Second, this is because the increase in Ees and the leftward shift of the ESPAR did not accompany the alteration in diastolic pressure-area relationship. In general, a smaller heart shows higher Ees with stiffer diastolic function (smaller end-diastolic volume with a given end-diastolic pressure), which results in reduced overall pump function (smaller stroke volume). In our patient there was no change in diastolic function after AVR. Thus the leftward shift of the ESPAR definitely implied improvement in overall LV pump function. Our view was 
supported by the improvement in the $\mathrm{dp} / \mathrm{dt}_{\max }$ to Amax ratio, another parameter of contractility, which is less sensitive to ventricular size or preload. ${ }^{8}$

The reduction in Msw, which is called preload recruitable stroke work, generally implies a decrease in contractility. ${ }^{7}$ In our patients reduced Msw could be explained by altered ejection physiology in AR. When forward stroke volume is maintained in AR, LV stroke volume (the difference between end-diastolic and end-systolic volume) is increased because of the excessive regurgitant volume. The low diastolic blood pressure in AR causes the increased rate and volume of blood flow into the aorta during early systole to midsystole, ${ }^{12}$ which results in wide pulse pressure but relatively normal end-systolic pressure. Early augmented ejection with increased LV stroke volume might imply reduced ejection load to the ventricle. This was indeed the case in our study because Ea was low before AVR and was increased after the operation. Ea is a parameter of ventricular afterload, which represents both pulsatile and static load to the ventricle, ${ }^{3,13}$ and is used to evaluate the interaction between the ventricle and the ejection load. According to Sunagawa and colleagues, ${ }^{3} \mathrm{SW}$ is determined by the interaction among Ea, Ees, and end-diastolic volume. The linearity and load independence of preload recruitable SW is considered to be due to the fact that SW is fairly constant when the value of $\mathrm{Ea}$ is in the normal range. ${ }^{14} \mathrm{In}$ our patients, however, there was a greater than $40 \%$ increase in Ea after AVR, which resulted in a decrease in SW. Because it has been shown that SW decreases when Ea is increased, ${ }^{15}$ it is conceivable that reduced Msw in our patients was due to the increase in Ea (below normal preoperatively returning to normal) after AVR.

Several previous studies support our view. Gaynor and coworkers ${ }^{16}$ performed an experimental study showing the increase of Msw after the creation of AR. Although they did not provide Ea data, their pressure-volume loops clearly demonstrated a widening of the loop (increased stroke volume) with no significant change in height (no change in Pes), indicating decreased Ea after the creation of AR. In another study Starling and colleagues ${ }^{17}$ made an interesting observation in patients who underwent AVR for AR. They measured maximal elastance (Emax; a term almost identical to Ees $^{6}$ ) before AVR and found that those who had had normal EF and mildly decreased Emax (group I) showed no change in EF (61\% to 63\%), those who had had mildly decreased EF and moderately decreased Emax (group II) showed an improvement in EF (50\% to 64\%), and those who had had severely decreased EF and Emax (group III) showed a further decrease in $\mathrm{EF}$ (35\% to $30 \%$ ). Why was there a decrease in EF in group III? The researchers did not perform a postoperative pressure-volume study, but it is highly conceivable that the postoperative Emax value improved in all patients because there was a significant reduc- tion in end-systolic volume in all patients. A further decrease in EF despite an increase in Emax in group III patients could be explained by the fact that the degree of increase in Ea after AVR was largest in these patients. The values of Ea calculated from their preoperative stroke volume and LV pressure data were $1.45,0.84$, and $0.58 \mathrm{~mm}$ $\mathrm{Hg} / \mathrm{mL}$, respectively, for groups I, II, and III. Thus normalization of Ea by AVR must have caused the largest increase in Ea for group III patients, which caused a decrease in EF. These data, including ours, indicate a close inverse relationship between the severity of AR and Ea.

In general, LV function improves after AVR in patients with AR. ${ }^{1,18,19}$ Most previous reports used EF to estimate contractility. There has been no post-AVR study that used Ees as the parameter of contractility under the framework of the pressure-volume relationship. The current study is also unique in elucidating load-independent ventricular function immediately after the discontinuation of cardiopulmonary bypass. Although load-independent indices are not available weeks or months after surgical intervention, it is highly conceivable that the improved contractile function observed in our study might continue to be improved because LV end-systolic volume is reported to be significantly reduced 3 to 6 months after AVR. ${ }^{17}$ Because Pes, which is very close to mean arterial pressure, is fairly constant, smaller volume with similar end-systolic pressure indicates that Ees is increased weeks or months after AVR.

The mechanism of the immediate recovery of contractility after AVR in our study is not clear. Reduction of LV volume caused a decrease in the work load of the left ventricle, with an increase in energy supply (higher diastolic blood pressure implying better myocardial perfusion). The improvement in the energy supply and demand ratio might have had a favorable effect in causing contractility enhancement. At the sarcomere level, reduction in volume after AVR, which caused the decrease in sarcomere length, might have optimized the operational length of the sarcomere. In terms of LV wall stress, the decrease in LV diameter after AVR should reduce the LV wall stress, which would work favorably for LV mechanics. A similar mechanism for explaining the improvement in ventricular volume or wall stress reduction operations (such as the Batista operation) or the Myosplint procedure has been advocated. ${ }^{20,21}$ Our results also might explain the mechanism of improved ventricular function observed after LV assist device implantation in some patients. ${ }^{22}$ Further study is warranted to elucidate the exact mechanism.

One might argue that these findings could be the result of cardiopulmonary bypass and not AVR. This might not be the case, however, because our preliminary results studying patients with aortic stenosis showed exactly the opposite response after AVR (ie, reduction in both Ees and Ea). Combining our current results and the described unpub- 
lished data, we might safely assume that the changes in loading condition has a significant influence on contractile function and that the findings obtained in our current study were the result of AVR and not the result of cardiopulmonary bypass.

Ees is the slope of the ESPAR, which is assumed to be a load-insensitive parameter of contractility. ${ }^{2}$ In addition to the size-dependent nature of the Ees, which has been already discussed in this article, the limitation of Ees includes curvilinearity of ESPAR when the contractility is either markedly increased or severely decreased. ${ }^{21}$ Among the parameters we used, the decrease in $\mathrm{A}_{100}$, es indicated shift to the left of ESPAR, which is independent of curvilinearity. In addition, the $\mathrm{dp} / \mathrm{dt}_{\max }$ to Aed ratio, another parameter of contractility that is assumed to be independent of loading conditions, was increased. These results support the conclusion of increased contractility after AVR.

Heart rate has positive effects on both Ees $^{23}$ and Ea. ${ }^{13}$ The increases in Ees and Ea might partly be due to the increase in heart rate observed in our patients. However, the increases observed in our patients (38\% increase in Ees and $47 \%$ increase in $\mathrm{Ea}$ ) were larger than the predicted increases in Ees of $13 \%{ }^{23}$ and $\mathrm{Ea}$ of $23 \%,{ }^{13}$ provided that the increase in heart rate from 73 to 90 beats/min was the only contributing factor for the increases in Ees and Ees. We thus assume that replacing the leaking valve with a competent valve was the major cause of the increases in Ees and $\mathrm{Ea}$ in our patients.

The approach of using LV cavity area as a surrogate for volume has been validated. $4,5,11$ We performed preliminary animal studies comparing CSA and LV volume measured either with a conductance catheter or with an isolated canine ejecting heart preparation. Both studies showed extremely linear correlation between the area and volume. We also found that the area signal was delayed for $40 \mathrm{~ms}$. On the basis of this finding, area signal in the present study was advanced for $40 \mathrm{~ms}$. Although previous validation studies support the use of area as a surrogate for volume, no validation study has been performed in the dilated heart, such as in our patients. In addition, rotational or swinging movement of the heart during one cardiac cycle might alter the relationship between cross-sectional cavity area and ventricular volume. Further investigation, such as that with 3-dimensional reconstruction of the LV cavity, should be performed to validate the methodology for applying this technique for hearts with abnormal geometry and movement.

The majority of our patients had normal EF preoperatively. Thus our results might not be able to be extrapolated to patients with AR with decreased EF. However, the results for patients with $\mathrm{AR}$ with low $\mathrm{EF}$ in the literature are encouraging, ${ }^{18,19}$ and accordingly, further study is warranted to elucidate the mechanism of improvement in the
LV function in patients with AR with the most decreased ventricular function.

We thank Dr Noriya Taki, the director of The Institute for Medical Statistics, for his work as a consultant statistician.

\section{References}

1. Krayenbuehl HP, Hess OM, Monrad ES, Schneider J, Mall G, Turina M. Left ventricular myocardial structure in aortic valve disease before, intermediate and late after aortic valve replacement. Circulation. 1989;79:744-55.

2. Sagawa K, Suga H, Shoukas AA, Bakalar KM. End-systolic pressure/ volume ratio: a new index of ventricular contractility. Am J Cardiol. 1977;40:748-53.

3. Sunagawa K, Maughan WL, Burkhoff D, Sagawa K. Left ventricular interaction with arterial load studied in isolated canine ventricle. Am J Physiol. 1983;245:H773-80.

4. Gorcsan J 3rd, Gaisior TA, Mandarino WA, Denault LG, Hattler BG, Pinsky MR. On-line estimation of changes in left ventricular stroke volume by transesophageal echocardiographic automated border detection in patients undergoing coronary artery bypass grafting. Am J Cardiol. 1993;72:721-7.

5. Gorcsan J 3rd, Lazar JM, Schulman DS, Follansbee WP. Comparison of left ventricular function by echocardiographic automated border detection and by radionuclide ejecition fraction. Am J Cardiol. 1993; 72:810-5.

6. Kass DA, Maughan WL. From "Emax" to pressure-volume relations: a broader view. Circulation. 1988;78:736-43.

7. Glower DD, Spratt JA, Snow ND, Kabas JS, Davis JW, Olsen CO, et al. Linearity of the Frank-Starling relationship in the intact heart: the concept of preload recruitable stroke work. Circulation. 1985;71:9941009.

8. Feldman MD, Pak PH, Wu CC, Haber HL, Heesch CM, Bergin JD, et al. Acute cardiovascular effects of OPC-18790 in patients with congestive heart failure: time and dose-dependence analysis based on pressure-volume relations. Circulation. 1996;93:474-83.

9. Gaash WH, Battle WE, Obolor AA, Banas JS Jr, Levine HJ. Left ventricular stress and compliance in man. With special reference to normalized ventricular function curves. Circulation. 1972;45:74662.

10. Suga H. Ventricular energetics. Physiol Rev. 1990;70:247-77.

11. Ochiai Y, Morita S, Tanoue Y, Kawachi Y, Tominaga R, Yasui H. Effects of amrinone, a phophodiesterase inhibitor on right ventricular/ arterial coupling immediately after cardiac operations. J Thorac Cardiovasc Surg. 1998;116:139-47.

12. Borow KM, Marcus RH. Aortic regurgitation: the need for an integrated physiological approach. J Am Coll Cardiol. 1991;17:898-900.

13. Kelly RP, Ting CT, Yang TM, Maughan WL, Chang MS, Kass DA. Effective arterial elastance as index of arterial vascular load in humans. Circulation. 1992;86:513-21.

14. Kass DA, Maughan WL, Guo ZM, Kono A, Sunagawa K, Sagawa $\mathrm{K}$. Comparative influence of load versus inotropic states on indexes of ventricular contractility: experimental and theoretical analysis based on pressure-volume relationships. Circulation. 1987;76: 1422-36.

15. Sunagawa K, Maughan WL, Sagawa K. Optimal arterial resistance for the maximal stroke work studied in isolated canine left ventricle. Circ Res. 1984;54:595-602.

16. Gaynor JW, Feneley MP, Gall SA Jr, Savitt MA, Silvestry SC, Davis $\mathrm{JW}$, et al. Left ventricular adaptation to aortic regurgitation in conscious dogs. J Thorac Cardiovasc Surg. 1997;113:149-58.

17. Starling MR, Kirsh MM, Montgomery DG, Gross MD. Mechanisms for left ventricular systolic dysfunction in aortic regurgitation: importance for predicting the functional response to aortic valve replacement. J Am Coll Cardiol. 1991;17:887-97. 
18. Carabello BA, Usher BW, Hendrix GH, Assey ME, Crawford FA, Leman RB. Predictors of outcome for aortic valve replacement in patients with aortic regurgitation and left ventricular dysfunction: a change in the measuring stick. J Am Coll Cardiol. 1987;10:991-7.

19. Carabello BA, Williams H, Gashi AK, Kent R, Belber D, Maurer A, et al. Hemodynamic predictors of outcome in patients undergoing valve replacement. Circulation. 1986;74:1309-16.

20. Dickstein M, Spotnitz HM, Rose EA, Burkhoff D. Heart reduction surgery. An analysis of the impact on cardiac function. J Thorac Cardiovasc Surg. 1997;113:1032-40.

21. McCarthy PM, Takagaki M, Ochiai Y, Young JB, Tabata T, Shiota T, et al. Device-based change in left ventricular shape: a new concept for the treatment of dilated cardiomyopathy. J Thorac Cardiovasc Surg. 2001; 122:482-90.

22. Hetzer R, Muller J, Weng Y, Wallukat G, Spiegelsberger S, Loebe M. Cardiac recovery in dilated cardiomyopathy by unloading with a left ventricular assist device. Ann Thorac Surg. 1999;68:742-9.

23. Maughan WL, Sunagawa K, Burkhoff D, Graves WL Jr, Hunter WC, Sagawa K. Effect of heart rate on the canine end-systolic pressurevolume relationship. Circulation. 1985;72:654-9.

24. Burkhoff D, Sugiura S, Yue DT, Sagawa K. Contractility-dependent curvilinearity of end-systolic pressure-volume relations. Am J Physiol. 1987;252:H1218-25.

\begin{abstract}
Online-www.aats.org
Now you can get The Journal of Thoracic and Cardiovascular Surgery online. The Journal online brings you faster delivery time, easy searching of current and back issues, links to PubMed, AATS, WTSA, and other important sites, and more. Visit the Journal online today.
\end{abstract}

\title{
Receive tables of contents by e-mail
}

To receive the tables of contents by e-mail, sign up through our Web site at http://www.mosby.com/jtcvs

Choose E-mail Notification

Simply type your e-mail address in the box and click the Subscribe button.

Alternatively, you may send an e-mail message to majordomo@mosby.com.

Leave the subject line blank and type the following as the body of your message: subscribe jtcvs_toc

You will receive an e-mail to confirm that you have been added to the mailing

list.

Note that TOC e-mails will be sent out when a new issue is posted to the Web site. 